ISSN 1112-9867

http://www.jfas.info

\title{
THE CONTENT ANALYSIS OF QUESTIONING LEVEL AT P4C CLASSROOM
}

\author{
T. Kamali Motlaq ${ }^{1}$ and N. Noushadi ${ }^{2, *}$ \\ ${ }^{1}$ M.A Student in Educational Research, Yasouj Univeresity, Yasouj, Iran \\ ${ }^{2}$ Department of Psychology, Yasouj University,75914-353 ,Yasouj, Iran
}

Published online: 15 May 2016

\begin{abstract}
This study attempts to see if there is any effect of philosophy for children method on student questioning level. To this end, randomized subjects, pretest-posttest control group design with random assignment (60 subjects in experimental groups and 60 subjects in control groups) were used. Pretest and posttest were implemented for each of two groups. Then the experimental group was trained by philosophy for children method, sessions once a week for six months. At the end of six months, posttest in both experimental and control groups was performed. The gathered data with using questioning Fisher method (2005) which was based on storytelling and using Philip Cam (1998) thinking stories books. Data were analyzed with quantitative content analysis and the following were found: teaching philosophy for children was significantly effective on the questioning level in experimental group. After teaching philosophy for children, level of questioning increased from "knowledge" to "analysis".
\end{abstract}

Keywords: Philosophy for children; elementary school; questioning level.

Author Correspondence, e-mail: noshadi5@ hotmail.com

doi: http://dx.doi.org/10.4314/jfas.v8i3s.262

\section{INTRODUCTION}

The major themes of Salinger's novels are children who carry the load of deposit through anecdote inquiry method. According to him, no one is truer than children. Children are mentor 
and touchstone and arbitrator of our world.

Salinger (1951) in "Catcher in the Rye" portrayed Holden Caulfield who was kicked out from school because he does not moulding according to the educational system and ask divergent questions. Caulfield is not interested in formal curriculum in classroom especially in social studies:

His concern that: I was wondering if lagoon would be frozen over when I got home, and if it was, where did the ducks and fish go. I was wondering where the ducks and fish went when the lagoon got all icy and frozen over.

His teachers said:

"Holden One short, faintly stuffy, pedagogical question. Don't you think there's a time and place for everything?

Holden answers:

"Yes-I don't know. I guess he should. But what I mean is, lots of time you don't know what interests you most till you start talking about something that doesn't interest you most".

This novel tells us that teachers need to learn empathy with student's questions and respect to other perspectives. Because teacher decision to use divergent question requires that it helps students to locate different sources of information so that they can share a variety of viewpoints in the class.

In philosophy, questioning begins with Socrates. Socrates believed that the distrust to reason questioner is associated with distrust to humans. Outcomes of this approach are intolerance, impatience and lack of error tolerance. Kolakowski (1999) said Socrates mission was to create doubt in the seemingly obvious. When Socrates recommended to his colleagues in the Phaedo, that care your soul, originally he felt grief in his heart regarding why questioning as a way of humility is not considered. Famous sentence, know yourself, insisted on the method of questioning to undertake a self-error and acknowledging that he knows what he does not know. For Socrates, attitude towards his young companions see most of the earlier dialogues, but also the Phaedo, where Socrates pleasant, kind, and respectful manner in which he listened to the young man's criticism is described (Popper, 1966). Foucault (2005) mentioned the care of the self as an ethical practice. Also, Rorty (1979) said since "education" sounds a bit too flat, I shall use "edification" to stand for this project of finding new, better, more interesting, more fruitful ways of speaking. The attempt to edify (ourselves or others) for connections between two cultures or disciplines and so on. Therefore, questioning is an 
attempt to edification, since the questioning is spiritual practice and has a moral dimension. And philosophy for children is a symbol of edification. Edification for Rorty equals with strong sense critical thinking for Paul related to each other. Strong-sense critical thinkers strive to be fair-minded. They use thinking in an ethically responsible manner. They work to understand and appreciate the viewpoints of others (Paul and Elder, 2002). Thus, to Paul, education toward critical thinking requires strategies that are both cognitive and moral (Daniel and Auriac, 2011). From this perspective, philosophy is not just an academic discipline. Philosophy belongs to everyone. All of us from childhood ask questions which have considerable philosophical aspects. The questioningly conscious children teach us that question more important answer and response more important answer. Answers carry the connotation of being final, complete, or the last word. To be sure, convergent questioning patterns may elicit student answers; but when divergent questions are framed, they will be providing responses that tend to be relative, less than certain, or tentative (Orlich, Harder, Callahan, Trevisan and Brown, 2010). The concept of "response" in "responsibility" means that teachers should be response to students's question. Therefore, philosophy for children is a movement for teacher's responsibility for children.

\section{STATE OF PROBLEM}

In epistemological view, questioning approach focuses on ignorance than knowledge. Socrates with applying this method concluded that he knows what he does not know anything. Therefore, teacher and student are lifelong learners. Then, self-knowledge means acceptance of ourselves error not escaping from it. In this view, idea of the teacher's authority solely stems from his consciousness of his own limitations and there is a relation of friendship between teacher and pupil (Popper, 1966). One of the reasons for overcoming the knowledge approach over ignorance is the predomination of idealism philosophy over synthesis philosophy. Harrison and Bramson (2002) concluded that idealist grand strategy is assimilative thinking (similarity) whereas synthesis grand strategy is the dialectic (difference). In knowledge approach, we feel that we know everything, and do not need other minds and the reality should be stature of our ideas and others think like us. Therefore, the outcome of 
this approach is common sense and conformity promotion. But, ignorance approach is based on the collective wisdom. The key idealists question is: who should plan people minds? This idealist question should change to synthesis question: how men actually do and how they might plan their minds? In synthesis approach, our opponents are not our enemies. We must learn from errors not to fled away, and as Zizek (2001) told: "Fear of error is error".

Questions can be critical elements for teachers to be used to stimulate student thinking and questioning plays a critical role in teaching. Merely asking questions does not cause student to think. If you ask a low level question, then you can expect a low level response. But, your higher level questions invite and encourage higher levels of critical thinking in students. Asking higher level questions also requires an adjustment in your attitude towards your students. Teachers must have high expectations from students. Your attitude should be yes, you can. Through appropriate questioning, student curiosity is fostered. Curiosity is an affective and moral dimension of learning, which means that it deals with the emotions and motivation. One of the most important questioning hierarchies is Bloom's taxonomy (cognitive domain). In the cognitive domain we have seen an increased emphasis on the development of student's thinking skills. Also, cognitive domain as a mean for classifying questions and their responses (Orlich, Harder, Callahan, Trevisan and Brown, 2010). Therefore, the function of philosophy for children is balancing between cognitive and affective domain.

Some of the educational presuppositions of philosophy for children are:

1-Chronological age is not a criterion, 2-The aim is not just content transmission from the old to the young, 3-Philosophy for children encourage children to acquire more general sorts of reasoning skills, 4-Remove philosophical terminology in the classroom, 5-Critical approach to issues, 6-Create a community of inquiry by questioning, 7- Heterogeneous classroom in opinion, 8- Intensify reflective dimension of the existing curriculum, and 9-Create an ethical community in classroom (Lipman and Sharp,1978).

Then, philosophy is not equal with learning philosophical ideas, but the teacher must be competent to lead philosophical discussions. Therefore, the instructional contexts of philosophy for children are: 1-after an error occurred by students, teacher must be educative 
than reprimand, because reprimand leads to shame. Shame is the feeling that I am a bad person, whereas error is the feeling that I have done a wrong response 2- predominant culture must be a culture of trust not to blame (students do not shame for question), 3-power should not be centralized, 4-teachers want the students desirous not flatterer, 5-environment is challenging and supporting innovation, 6-teachers want the students empowerment not powerful.

Also, a redefined power is on the agenda: inner power than outer power. Inner power and inner peace are together. Therefore, the mission of philosophy for children is to help students and teachers to more compassionate human person and self-aware. In traditional view, compassion, caring others, and kindness are sign of weakness and treat, but in new vision, they are sign of strength and opportunity to construct our world. Therefore, teacher and students become philosophers. Philosophy for children is the solution for Kant (1900) paradox, "how is it possible to cultivate freedom through coercion?"

\section{RESEARCH QUESTIONS}

1-What is the level of student's questions in pre-test?

2- What is the level of student's questions in post-test?

\section{POPULATION AND SAMPLE}

The population in this study was including all elementary school girl students in Isfahan in academic year 2014-2015. The sample includes 120 students (60 subjects in experimental group and 60 subjects in control group). Pre-test and post-test were implemented for two groups. Also, for each six grade of elementary division, 10 students participated.

Then, the experimental group was trained in philosophy for children method, sessions once a week for six months. At the end of six months, post-test in both experimental and control groups were performed. The gathered data with using Fisher's questioning method (2005) which was based on storytelling and using Philip Cam (1998) thinking stories books. After reading the stories, individually or in groups, each child asked three questions, the questions were written on a poster in order to collect and present the interest to the community. When 
all the questions had been written, the teacher helped the community to classify questions and share meaning to them. In the following, by using cognitive level of Bloom's taxonomy (1956) (knowledge, comprehension, application, analysis, synthesis, evaluation) data (student's questions) is analyzed with quantitative content analysis.

\section{RESEARCH METHOD}

The research method of present study is randomized subjects, pre-test - post-test control group design. The main strength of this design is initial randomization and according to Campbell and Stanley (1963) this design has internal validity such as: history, maturation, statistical regression and differential selection of subjects (Ary, Jacobs, Sorenson and Razavieh, 1996).

Table 1. Randomized subjects, pre-test - post-test control group design.

\begin{tabular}{ccccc}
\hline Random assignment & Group & Pre-test & Independent variable & Post test \\
\hline$R$ & E & + & + & + \\
\hline$R$ & C & + & - & + \\
\hline
\end{tabular}

\section{RESULTS}

In this section, we answer the following research questions:

1-What is the level of student's questions in pre-test?

Table 2. Content analysis of questioning level based on cognitive domain (Pre-test)

\begin{tabular}{lccccccc}
\hline Group & knowledge & Comprehension & Application & Analysis & Synthesis & Evaluation & total \\
\hline Control & 115 & 37 & 1 & 21 & 6 & 0 & $\mathbf{1 8 0}$ \\
\hline Experimental & 126 & 36 & 0 & 11 & 7 & 0 & $\mathbf{1 8 0}$ \\
\hline
\end{tabular}


Table 3. Content analysis of questioning level for each grade based on cognitive domain

(Pre-test)

\begin{tabular}{|c|c|c|c|c|c|c|c|c|}
\hline Group & Grade & knowledge & Comprehension & Application & Analysis & Synthesis & Evaluation & total \\
\hline & 1 & 24 & 5 & 1 & 0 & 0 & 0 & 30 \\
\hline & 2 & 24 & 5 & 0 & 1 & 0 & 0 & 30 \\
\hline \multirow[t]{4}{*}{ Control } & 3 & 19 & 4 & 0 & 7 & 0 & 0 & 30 \\
\hline & 4 & 17 & 8 & 0 & 3 & 2 & 0 & 30 \\
\hline & 5 & 14 & 7 & 0 & 7 & 2 & 0 & 30 \\
\hline & 6 & 17 & 8 & 0 & 3 & 2 & 0 & 30 \\
\hline \multirow[t]{3}{*}{ Sum } & & 115 & 37 & 1 & 21 & 6 & $\mathbf{0}$ & 180 \\
\hline & 1 & 29 & 1 & 0 & 0 & 0 & 0 & 30 \\
\hline & 2 & 27 & 0 & 0 & 1 & 2 & 0 & 30 \\
\hline \multirow[t]{4}{*}{ Experimental } & 3 & 20 & 7 & 0 & 1 & 2 & 0 & 30 \\
\hline & 4 & 18 & 10 & 0 & 2 & 0 & 0 & 30 \\
\hline & 5 & 17 & 11 & 0 & 2 & 0 & 0 & 30 \\
\hline & 6 & 15 & 7 & 0 & 5 & 3 & 0 & 30 \\
\hline Sum & & 126 & 36 & $\mathbf{0}$ & 11 & 7 & $\mathbf{0}$ & 180 \\
\hline
\end{tabular}

For analyzed data (students questions) the chi-square were used. Findings show that there is no significant difference between observed and expected frequency in student's questions at control and experimental in pre-test. And the most students question are at knowledge level (Tables $2 \& 3$ ).

2- What is the level of student's questions in post-test?

Table 4. Content analysis of questioning level based on cognitive domain (Post-test)

\begin{tabular}{lccccccc}
\hline Group & knowledge & Comprehension & Application & Analysis & Synthesis & Evaluation & total \\
\hline Control & 138 & 30 & 0 & 6 & 6 & 0 & $\mathbf{1 8 0}$ \\
\hline Experimental & 20 & 53 & 0 & 76 & 31 & 0 & $\mathbf{1 8 0}$ \\
\hline
\end{tabular}


Table 5. Content analysis of questioning level based on cognitive domain (Post-test)

\begin{tabular}{|c|c|c|c|c|c|c|c|c|}
\hline Group & Grade & knowledge & Comprehension & Application & Analysis & Synthesis & Evaluation & total \\
\hline & 1 & 25 & 5 & 0 & 0 & 0 & 0 & 30 \\
\hline & 2 & 20 & 9 & 0 & 1 & 0 & 0 & 30 \\
\hline \multirow[t]{4}{*}{ Control } & 3 & 23 & 6 & 0 & 0 & 1 & 0 & 30 \\
\hline & 4 & 23 & 4 & 0 & 0 & 3 & 0 & 30 \\
\hline & 5 & 27 & 2 & 0 & 0 & 1 & 0 & 30 \\
\hline & 6 & 20 & 4 & 0 & 5 & 1 & 0 & 30 \\
\hline \multirow[t]{3}{*}{ Sum } & & 138 & 30 & $\mathbf{0}$ & 6 & 6 & $\mathbf{0}$ & 180 \\
\hline & 1 & 0 & 8 & 0 & 12 & 10 & 0 & 30 \\
\hline & 2 & 15 & 0 & 0 & 9 & 6 & 0 & 30 \\
\hline \multirow[t]{4}{*}{ Experimental } & 3 & 2 & 11 & 0 & 16 & 1 & 0 & 30 \\
\hline & 4 & 0 & 12 & 0 & 15 & 3 & 0 & 30 \\
\hline & 5 & 1 & 10 & 0 & 14 & 5 & 0 & 30 \\
\hline & 6 & 2 & 12 & 0 & 10 & 6 & 0 & 30 \\
\hline Sum & & 20 & 53 & $\mathbf{0}$ & 76 & 31 & $\mathbf{0}$ & 180 \\
\hline
\end{tabular}

For analyzed data (students questions) the chi-square were used. Findings show that there is significant difference between observed and expected frequency in student's questions at control and experimental in post-test. In control group, more student's questions are at knowledge level, but in experimental group, more student's questions are at analysis level. In other word, philosophy for children leads to promotion of student's questions from "knowledge" to "analysis" level (Tables 4 \& 5).

\section{DISCUSION AND INSIGHTS}

The goal of this study was to determine cognitive level on students questioning in philosophy for children classroom. By using quantitative content analysis, student's questions was analyzed. The result showed that before teaching philosophy for children to, each control and experimental group, there is no significant difference between observed and expected 
frequency. In other word, the most questions of student are "knowledge" level.

On the other hand, after teaching the philosophy for children, there is significant difference between observed and expected frequency in experimental group. But, in control group the most students question were knowledge but in experimental group the most students questions were analysis.

Philosophy for children is an international movement that aims to give voice to children thinking through philosophical practice. Philosophy for children is based on the proposition that critical thinking and dialogue are the necessary conditions for emancipating children from determination and for transforming them into democratic, free citizens. (Vansieleghem, 2005). By combining research findings (tables 2 to 5) and theoretical foundation such as theory of mind and conceptual framework, such as Dewey "plasticity"; Merleau-Ponty "Polymorph"; Piaget "centration and decentration"; Foucault "Power and knowledge"; Kegan "interpersonal and institutional"; Maslow "social need"; Freire "culture of silence"; Gramsci "cultural hegemony", we can explain effects of philosophy for children.

Eisner (2002) said, brain is biological and mind is cultural. He concluded that teacher's viewpoint should not be about biological aspects. Also, Hegel wrote mind is never at rest but always engages in ever progressive motion, in giving itself a new form.

Then, silence in classroom has cultural background, because this motion can be positive or negative. If in classroom, teacher provides the opportunity for questioning and creating a positive atmosphere in classroom then, children and teacher do not threat for together, and it would increase brain neuropath. In other word, mind with more interaction make more neuropath and thus the brain becomes more advanced. This helps to the educational leadership to lead mind motion to creation, but not creativity that relating to a special group or a special time, but gradually scope of thinking. Therefore, philosophy for children causes the child to continuously reduce subjectivity and to add objective until the child can define him/her self. If child do not pass from this point and do not construct a bridge, then s/he remain immature. Child through questioning can construct a positive image that in interaction with others than contrast with others, and do not see her/his success in defeating others but in collaboration with others. Then, the reason of the generation gap is raise by teachers depriving 
the right to define children by questioning. Then, teachers are more than responsibility, concerned with guardian of child. In this educational system, it is assumed that students are immature and need guardian teachers. This approach is based on genetic epistemology and Locke mind is blank slate. The outcomes of this assumptions is, culture of silence in the classroom and hiding the question by the teacher and student, because knowledge is power. Students for this reason do not ask question, because until others have less opportunity to learn. On the other hand, in the absence of questioning, teacher's hegemony continues on students by hidden ignorance. And this vicious cycle leading to reproduction of replica by suppression of questioner's inquisitiveness.

And its mechanism is as follows; the conversion of the Ministry of Education to Orwell's Ministry of Truth manifests: "ignorance is strength". The Ministry of Truth (propaganda) deals with news, entertainment, education and art (Orwell, 1949). The outcomes of this approach are reproduction of the best (survival of the best). The best cannot survive on questioner citizens.

Then the key question at $\mathrm{p} 4 \mathrm{c}$ classroom is: how can we have educational system that students will be involved in issues?

\section{REFERENCES}

[1] Ary, D, Jacobs, L.C \& Razavieh, A. (1996). Introduction to Research in Education. Harcourt Brace College Publishers.

[2] Bloom, B., Engelhart, M., Krathwohl, D. (1956). Taxonomy of Educational Objectives. The Classification of Educational Goal. Handbook 1: Cognitive Domain. New York: David McKay.

[3] Cam, P. (1998). Thinking stories 1. Hale \& Iremonger, Pty. Ltd, Australia

[4] Daniel, M, F \& Auriac, E. (2011). Philosophy, Critical Thinking and Philosophy for children. Educational Philosophy and Theory, Vol. 43, No. 5.

[5] Eisner, E. W. (2002). The Arts and Creation of Mind. Yale University Press.

[6] Fisher, R. (2005). Teaching Children to Think (2 th). London. Nelson Thornes.

[7] Foucault, M. (2005). The Hermeneutics of the subject: lecture at the college defrance, 1981-82, G. Burchill, trans. (New York, Palgrave Macmillan). 
[8] Harrison. A and Bramson. R. (2002). The art of thinking. Berkely Publishing Group.

[9] Kant, I. (1900). On Education. (Trans. Annette Churton). Boston: DC. Heath and Co.

[10]Kolakowski, L. (1999). Mini lectures on maxi issues. Krakow: ZNAK, 1999.

[11]Lipman, M \& Sharp, A, M. (1978). Some Educational Presuppositions of philosophy for children. Oxford Review education, Vol. 4, No.1.85-90.

[12] Orlich, D; Harder, R; Callahan, R; Trevisan, M \& Brown, A. (2010). Teaching strategies: A guide to effective instruction. Wadsworth, Cengage Learning.

[13] Orwell, G. (1949). Nineteen Eighty-Four. A novel. New York: Harcourt, Brace \& Co.

[14]Paul, R., \& L. Elder. (2008). The miniature Guide to Critical Thinking Concepts and Tools. Dillon Beach, CA: Foundation for Critical Thinking.

[15]Popper, K. (1966). Open society and its enemies. PENN, Bachinghamshire.

[16]Rorty, R. (1979). Philosophy and the mirror of nature. Princeton university press.

[17] Salinger, J. D. (1951). The catcher in the rye. Little, Brown and Company.

[18]Zizek, S. (2001). Enjoy you symptom: Jacques Lacan in Hollywood and out. Routledge.

\section{How to cite this article:}

Kamali Motlaq $\mathrm{T}$ and Noushadi N. The content analysis of questioning level at p4c classroom. J. Fundam. Appl. Sci., 2016, 8(3S), 803-813. 